\title{
Presencia de bacterias rizosféricas resistentes a mercurio en suelos del sur de Bolívar, Colombia
}

\section{Presence of mercury-resistant rhizosphere bacteria in soils in the Southern Bolívar, Colombia}

\author{
Paternina H Ramón ${ }^{1}$ Ing. Amb y Sanit, Pérez C Alexander² Ph.D, Vitola R Deimer ${ }^{3}$ Biol. \\ ${ }^{1}$ Corporación Autónoma Regional de Sucre- CARSUCRE, fortalecimiento del programa y \\ monitoreo del recurso hídrico, Sincelejo, Colombia. \\ ${ }^{2}$ Universidad de Sucre, Facultad de Ciencias Agropecuarias, departamento de Fitotecnia, \\ Grupo de investigación en Bioprospección Agropecuaria, Sincelejo, Colombia. \\ ${ }^{3}$ Universidad de Sucre, grupo de investigación Bioprospección Agropecuaria, Sincelejo, Colombia.
}

Keywords:

Bacteria;

rhizosphere;

mercury;

resistance.

\begin{abstract}
The objective of the present study was to isolate rhizospheric bacteria from samples from the Santa Cruz Mine, department of Bolivar, in order to evaluate in vitro resistance activity at different concentrations of mercury. The samples were collected randomly from different sites near the Santa Cruz gold mine, from which they isolated rhizospheric bacteria. The resistance capacity of bacteria at different concentrations of mercury in the form of mercury chloride $\left(\mathrm{HgCl}_{2}\right)$ at concentrations of $50 \mathrm{ppm}, 100 \mathrm{ppm}, 150 \mathrm{ppm}$, $200 \mathrm{ppm}$ and $250 \mathrm{ppm}$ was evaluated in vitro; also the bacteria resistant to this metal were used to evaluate the ability to promote growth in plants. The results showed that the bacterium identified as Pseudomonas luteola, resisted in vitro at $200 \mathrm{ppm}$ of mercury chloride $(\mathrm{HgCl} 2)$, and qualitatively had the ability to produce siderophores and biologically fix nitrogen. $P$ luteola was isolated from the rhizosphere near the Santa Cruz mine in the department of Bolivar, Colombia, with soils with high concentrations of mercury and extremely acidic soil reaction.
\end{abstract}

\section{Resumen}

El objetivo del presente estudio fue aislar bacterias rizosféricas de muestras provenientes de la Mina de Santa Cruz, departamento de Bolívar, con el propósito de evaluar in vitro la actividad de resistencia a diferentes concentraciones de mercurio. Las muestras fueron recolectadas aleatoriamente de diferentes sitios de cerca de la mina de oro Santa Cruz, a partir de la cuales de aislaron bacterias rizosférico. Se evaluó in vitro la capacidad de resistencias de las bacterias a diferentes concentraciones de mercurio en forma de cloruro de mercurio $\left(\mathrm{HgCl}_{2}\right)$ a concentraciones de 50 ppm, 100 ppm, 150 ppm, 200 ppm y 250 ppm; así mismo las bacterias resistentes a este metal se utilizaron para evaluar la capacidad de promoción de crecimiento en las plantas. Los resultados mostraron que la bacteria identificada como Pseudomonas luteola, resistió in vitro a 200 ppm de cloruro de mercurio $\left(\mathrm{HgCl}_{2}\right)$, y cualitativamente tuvo la capacidad de producir sideróforos y fijar biológicamente nitrógeno. $P$ luteola fue aislada de la rizósfera cerca de la mina de Santa Cruz en el departamento de Bolívar, Colombia, con suelos con altas concentraciones de mercurio y con reacción del suelo extremadamente acida. 


\section{Introducción}

La contaminación de los ecosistemas por metales pesados es uno de los principales objeto de estudios de las ciencias relacionadas con el ambiente. Esto es debido a que esas sustancias químicas presentan alta toxicidad y propiedades de acumulación en los organismos. Los residuos generados por la industria pueden contener uno o más metales tóxicos, y dan orígenes a efluentes químicamente complejos. El mercurio es un metal pesado altamente tóxico y un contaminante global referenciados en diversas literaturas científicas, el cual es continuamente depositado en los ecosistemas terrestre y acuáticos y la reemisión de nuevo a la atmósfera a través de fuentes naturales (CHUNG y CHON, 2014), dentro la cuales se encuentran las emisiones de reservorios naturales como las actividades volcánicas y los incendios forestales; y la reemisión del mercurio depositada a través de fuentes antropogénicas y naturales (ZHANG et al., 2014). Estudios recientes y los modelos del ciclo en el medio ambiente, estima que las emisiones de mercurio y las reemisiones desde el suelo y la vegetación es de aproximadamente 5500 - 8900 toneladas, incluyendo además un $19-51 \%$ de emisión a la atmósfera a través de otras las fuentes (UNEP, 2013).

ZHOU et al., (2015), han señalado que la emisión del mercurio a partir de los bosques y las praderas se han convertido en una fuente importante del total del mercurio gaseoso que se encuentra en la atmósfera, por lo que, el flujo de intercambio suelo/ aire es un componente importante dentro del ciclo biogeoquímicos del mercurio total. La toxicidad y los efectos adversos del mercurio en la salud humana y en los ecosistemas han sido dados a conocen desde hace mucho tiempo atrás. Los suelos contaminados contribuyen con la contaminación global de este metal y el impacto directo que tiene sobre el agua, vegetación, el aire y las consecuencias para la salud humana y animal. Las formas orgánicas de metil-mercurio $\left(\mathrm{MeHg}^{+}\right.$) y etil-mercurio $\left(\mathrm{EtHg}^{+}\right)$, son las formas más móviles, toxicas y bioacumulables, con respecto a las formas inorgánicas (BLOOM y PORCELLA, 1994). El mercurio en el suelo intercambia entre formas orgánicas e inorgánicas dependiendo de los factores físico-químicos y ambientales (YASUTAKE et al., 2011).
Según lo manifiesta PAISIO et al., (2012), el mercurio $(\mathrm{Hg})$ se encuentra en la naturaleza en forma inorgánica: elemental $\mathrm{Hg}(0)$ o iónicas $\mathrm{Hg}$ (I y II) y orgánicas: metilmercurio $\left(\mathrm{CH}_{3} \mathrm{Hg}\right)$ (MeHg), dimetilmercurio $\left(\mathrm{CH}_{3}\right)_{2} \mathrm{Hg}$ y fenilmercurio $\left(\mathrm{C}_{6} \mathrm{H} 5 \mathrm{Hg}\right)$. El Hg (II) tiende a unirse fuertemente a los componentes del suelo, lo cual reduce su biodisponibilidad. Las formas orgánicas de este metal pesado, principalmente el $\mathrm{MeHg}$, son altamente tóxicas y se acumulan en membranas biológicas. Una vez presente en el medioambiente, el $\mathrm{Hg}(0)$ se oxida a Hg iónico, el cual se deposita eficientemente en el suelo y/o agua y es convertido en $\mathrm{MeHg}$ por bacterias anaeróbicas reductoras de sulfuro.

WANG et al., (2012), señalan que el mercurio se encuentra en el ambiente a partir de diversas fuentes, incluyendo naturales y antropogénicas. Su deposición natural en suelos proviene de la meteorización de rocas, de eventos volcánicos y actividad geotérmica, en concentraciones entre 0.03 y $0.1 \mathrm{mg} / \mathrm{Kg}$ ). Con relación a las fuentes de procedencia antropogénicas, las actividades mineras son una de las principales vías de ingreso directo de $\mathrm{Hg}$ dentro del ambiente, particularmente las de explotación de oro y plata.

De lo antes, expuesto surge la necesidad inmediata de contribuir a mitigar el $\mathrm{Hg}$ en los sitios contaminados, con el propósito de reducir los riesgos para el ambiente y en la salud de los organismos incluyendo al hombre. En este sentido, el desarrollo de nuevas tecnologías de remediación ambiental es en la actualidad un campo de investigación de mucho interés. Existen métodos físico-químicos y biológicos de remoción $\mathrm{de} \mathrm{Hg}$ de efluentes industriales; de suelos y aguas contaminadas. Sin embargo, como lo manifiesta GERHARDT et al., (2009), los métodos físico - químicos, poseen algunas desventajas, tales como sus altos costos, utilización de grandes cantidades de reactivos y sus efectos adversos sobre los ecosistemas, entre otros. Surge la necesidad de aplicar tecnologías de remediación más eficientes y ambientalmente "amigables", como los métodos de remediación biológica, los cuales utilizan organismos vivos para reducir, eliminar, contener o transformar los contaminantes en suelo, agua y aire. 
Algunas bacterias son capaces de resistir a la contaminación de metales pesados a través de la transformación química por reducción, oxidación, metilación y la desmetilación. El mecanismo de resistencia más ampliamente descripto para este metal se basa en la presencia de grupos de genes organizados en un único operón, denominado "operón mer", que permite la detoxificación enzimática del metal conocido hasta el momento que permite la transformación de formas tóxicas a formas no toxicas volátiles (MATHEMA et al., 2011).

Así, el objetivo del presente estudio fue aislar bacterias del suelo provenientes de la Mina de Santa Cruz, departamento de Bolívar, Colombia y evaluar in vitro la resistencia a diferentes concentraciones de mercurio con el propósito de encontrar bacterias del suelo que a futuro se conviertan en alternativa biológica para mitigar el efecto de este metal en el suelo.

\section{Materiales y métodos}

Sitio de muestreo. Para la selección del sitio de muestreo, se tomó como referencia, el levantamiento de información bibliográfica con reporte de ambientes contaminados con mercurio en el caribe colombiano presentado por PÉREZ et al., (2016). Se identificó el corregimiento de Mina Santa Cruz, pertenecientes al municipio de San Martin de Loba, localizado en el sur de Bolívar, Colombia. Las coordenadas geográficas del sitio de muestreo correspondió a: $08^{\circ} 46.42^{\prime} 08^{\prime \prime}$ latitud Norte y $74^{\circ} 10.21^{\prime}, 02$ " longitud. Este. El corregimiento de Mina Santa Cruz, presenta como principal actividad la explotación artesanal de oro, el proceso de extracción de este metal implica el uso de altas concentraciones de mercurio el cual llega al suelo, debido a que las corrientes acuosas que salen de los molinos de la amalgamación y a la quema de mercurio, para su purificación de oro. En la Figura 1 se muestra la georeferenciación de la Mina de Santa Cruz, departamento de Bolívar, Colombia.

En los sitios de muestreo, se recolectaron muestras en una extensión de una hectárea, llevando a cabo marcación de los puntos de muestreo al azar y abarcando toda el área seleccionada. Para la toma de las muestras, se utilizó la metodología propuesta por el IGAC, (2015). De cada sitio demarcado se recolectaron muestras de suelo y suelos con raíces de plantas; las cuales fueron rotuladas y conservadas para su transporte. Las muestras de suelo fueron utilizadas para caracterización física -química en el laboratorio de suelos y aguas de la Universidad de Sucre y las muestras de suelos más raíces se utilizaron para el aislamiento de bacterias rizosféricas y pruebas de resistencia in vitro a diferentes concentraciones de mercurio.

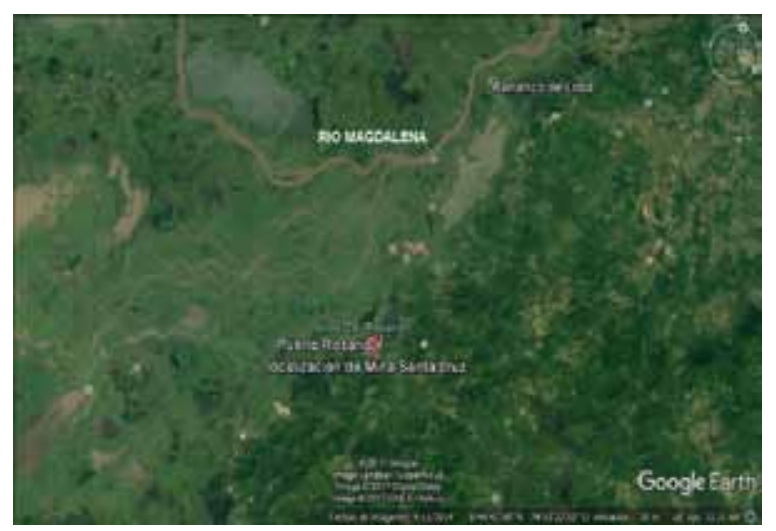

Figura 1. Mina de Santa Cruz, departamento de Bolívar, Colombia. Fuente: http//google earth, 2017.

Aislamiento de bacterias rizosféricas. Se aislaron bacterias de suelo rizosférico. Para el aislamiento de las bacterias rizosféricas se utilizó el protocolo propuesto por MURATOVA et al., (2003), el cual consistió en remover el suelo no rizosférico de las raíces; la raíz con suelo rizosférico adherido se lavó en $100 \mathrm{~mL}$ de agua destilada y se agitó por 30 minutos. Se dejaron sedimentar las partículas de suelo y con la suspensión se prepararon diluciones seriadas desde $10^{-1}$ a $10^{-7}$, las cuales fueron inoculadas sobre la superficie de agar McConkey por triplicado y se incubaron a $33 \pm 2{ }^{\circ} \mathrm{C}$ por 72 horas. Después de este tiempo, se seleccionaron aquellas colonias con características visibles en cuanto a forma, color, tamaño y consistencia y se conservaron en agar nutriente $a 4^{\circ} \mathrm{C}$. La densidad de bacterias, en UFC/g de suelo, fue estimada por conteo directo de colonias sobre la superficie de los medios agar nutritivo y McConkey. Durante el conteo fueron observadas y seleccionadas las colonias que se distinguían en cuanto a forma, aspecto de la superficie, color y tamaño. Los morfotipos seleccionados fueron purificados y mantenidos en agar nutritivo para su posterior análisis e identificación. 
Pruebas de Resistencia a Mercurio. Los morfotipos de bacterias más predominantes fueron purificados y usados para evaluar in vitro la sensibilidad o resistencia a diferentes concentraciones de mercurio. El nivel de resistencia de bacterias a mercurio se evaluará en medio Tris-tampón bajo en fosfato (TLP) propuesto por RATHNAYAKE et al., (2013). Los aislamientos fueron inoculados en medio TLP enriquecido con $\mathrm{Hg}$, en forma de cloruro de mercurio $\left(\mathrm{HgCl}_{2}\right)$ con diferentes concentraciones (50 ppm, 100 ppm, 150 ppm, 200 ppm y 250 ppm) .Para cada uno de los aislamientos, la concentración mínima y máxima que inhibe el crecimiento visible se determinará después de la incubación a $28^{\circ} \mathrm{C}$ por 7 días. La determinación cualitativa del crecimiento se efectuará mediante observación del crecimiento de las bacterias en el medio. Las bacterias con presencia de tolerancia a mercurio fueron purificadas y conservadas para su posterior evaluación de la actividad promotora del crecimiento.

Actividades promotoras de crecimiento. Los morfotipos que mostraron in vitro resistencia a mercurio, fueron purificados y utilizado para evaluar cualitativamente las siguientes actividades:

Fijación biológica de nitrógeno. La evaluación cualitativa de la fijación biológica de los aislamientos se realizó por la metodología descrita por PÉREZ et al., (2014) en medio selectivo agar ASHBY. Cada uno de los morfotipos de aislamientos fueron sembrados en forma directa sobre la superficie del medio e incubados a $28^{\circ} \mathrm{C}$ por 72 horas. Después de este tiempo, se seleccionaron los morfotipos que fueron capaces de crecer en el medio, indicando la presencia de aquellas bacterias endófitas que poseen el sistema enzimático que les permite reducir el nitrógeno atmosférico y utilizarlo en su metabolismo.

Solubilización de fosfatos. Para la evaluación cualitativa de la solubilización de fosfato de los aislamientos, se realizó, siguiendo la metodología propuesta por PÉREZ et al., (2014), sobre medio NBRIP con $\mathrm{Ca}_{3} \mathrm{PO}_{4}$ como fuente de fósforo insoluble a $\mathrm{pH}$ 7. Cada morfotipo fue inoculado sobre la superficie del medio e incubado a $28{ }^{\circ} \mathrm{C}$ por 72 horas. La observación cualitativa de los aislados se determinó por observación de la formación de halo transparente visible alrededor y debajo de la colonia.
Producción de sideróforos. La producción de sideróforos fue realizado sobre el medio cromo azurol-S (CAS) propuesto por SCHWYN y NEILANDS (1987), y evaluado por PÉREZ et al., 2017; el cual consistió en disolver $60.5 \mathrm{mg}$ de CAS en $50 \mathrm{ml}$ de agua destilada, a esta mezcla se le adicionó $10 \mathrm{ml}$ de solución de hierro (III) (1 mM de $\mathrm{FeCl}_{3} \cdot 6 \mathrm{H}_{2} \mathrm{O}$ y $10 \mathrm{mM}$ de $\mathrm{HCl}$ ), bajo agitación. La solución se mezcla con $72.9 \mathrm{mg}$ de HDTMA disuelto en $40 \mathrm{ml}$ de agua. El líquido azul resultante se autoclavó a $121^{\circ} \mathrm{C}$ por 15 minutos. En otro recipiente también se autoclavó una mezcla de $750 \mathrm{ml}$ de agua, $15 \mathrm{gr}$ de agar, 30.24 $\mathrm{g}$ de pipes, y $12 \mathrm{~g}$ de una solución $50 \%$ (w/w) de $\mathrm{NaOH}$ ajustado a $\mathrm{pH}$ de 6.8. Al medio se le agregaron $4 \mathrm{~g}$ de glucosa como fuente de carbono. Las aislados se sembraron utilizando palitos de madera y se incubaron durante 7 días a $30^{\circ} \mathrm{C}$. La habilidad de la bacteria para producir sideróforos se evidenció por la formación de un halo.

Identificación de la bacteria rizosféricas resistentes a mercurio. Para la identificación de bacterias rizosféricas que mostraron resistencia a mercurio y actividad positiva para la fijación biológica de nitrógeno, solubilización de fosfato, producción de sideróforos; se realizó la prueba de oxidasa, observación de la bacteria con tinción diferencial y siembra en medios selectivos agar MacConkey, Agar EMB y cetrimida. La identificación se llevó a cabo por medio de diferentes pruebas bioquímicas que se contenían en una galería plástica con micro tubos con cultivos deshidratados o que contenían sustratos de diferentes enzimas, en este caso se utilizó el sistema miniaturizado API20 NE, el cual arrojo un perfil numérico que se ingresó a la página web https://apiweb.biomerieux.com y permitió la identificación de la bacteria

\section{Resultados y discusión}

Análisis físico-químico del suelo. Los resultados de la caracterización de los parámetros físicoquímicos encontrados en la muestra de suelo recolectada en la zona de Mina Santa Cruz, se describen en la Tabla 1.

Los resultados mostrado en la Tabla 1 señalan que los suelos presentaron las siguientes características físico-química: valores de $\mathrm{pH}$ 
Tabla 1. Análisis físico-químico de suelos de la Mina de Santa Cruz, Bolívar, Colombia

\begin{tabular}{cccc}
\hline Parámetros Físico-químicos & Valor & Interpretación & Valores referencias \\
\hline pH (Agua 1:1 P/V) & 2,36 & Extremadamente ácido & $5,80-7,20$ \\
Materia orgánica (\%) & 0,78 & Contenido muy pobre & $2,0-4,0$ \\
Fósforo (ppm), Bray II & 57,72 & Contenido alto & $15-30$ \\
C.I.C. (meq/100 gr de suelo) & 12,50 & Contenido moderado & $10-20$ \\
Calcio (Cmol.kg-1 suelo) & 0 & Nulo & $5-7$ \\
Magnesio (Cmol.kg-1 suelo) & 0 & Nulo & $2-3$ \\
Potasio (Cmol.kg-1 suelo) & 0,01 & Contenido muy pobre & $0,2-0,4$ \\
Sodio (Cmol.kg-1 suelo) & 2,3 & Contenido abundante & $<1,0$ \\
Aluminio intercambiable (Cmol.kg-1 suelo) & 15 & Contenido excesivo & $<0,2$ \\
Azufre, ppm, fotométrico, IGAC 6 Ed 2006 & 3624 & Contenido excesivo & Franco arcilloso \\
Textura (M. Bouyoucos) & F.L & Franco Limoso & $20-50$ \\
Arena (\%) & 23,33 & & $20-60$ \\
Arcilla (\%) & 13,33 & & $20-70$ \\
Limo (\%) & 63,34 & & $50-70$ \\
Saturación de calcio (\%) & 0 & Contenido muy pobre & $20-30$ \\
Saturación de magnesio (\%) & 0 & Contenido muy pobre & $<6,0$ \\
Saturación de sodio (\%) & 13,29 & Contenido abundante & $<5,0$ \\
Saturación de aluminio (\%) & 86,66 & Contenido excesivo & - \\
Relación calcio /magnesio & 0 & Suelo sódico & $2-4$ (normal) \\
Conductividad eléctrica (MicroS/cms) & 8050 & - & - \\
Salinidad \% en pasta saturada & 4,5 & & 2.000
\end{tabular}

Fuente. Laboratorio suelos y aguas de la Universidad de Sucre, 2017.

extremadamente ácido; contenidos de materia orgánica, potasio, saturación de calcio y magnesio muy pobres; de fósforo alto; aluminio intercambiable y azufre excesivo; capacidad de intercambio catiónico moderado; calcio y magnesio nulos; sodio y saturación de sodio abundante; la conductividad eléctrica indicó un suelo sódico y textura franco limosa.

Como lo manifiesta PÉREZ et al., (2016) y lo corroboran KABATA-PENDIAS (2011) y TERÁNMITA et al., (2013), presencia de valores de $\mathrm{pH}$ extremadamente ácido encontrado en los suelos de la zona del presente estudio, sugieren que la absorción del mercurio es alta y, como consecuencia, es fácilmente transportado en el suelo por escorrentía hacia cuerpos de agua aledaños. Asimismo, el contenido excesivo de aluminio en estos suelos está muy relacionado con el $\mathrm{pH}$ ácido del mismo, lo que posiblemente causaría inhibición del crecimiento radical y, como resultado, reducción en la toma de agua y de nutrientes por parte de las plantas establecidas en esos suelos (CASIERRA- POSADA y AGUILARAVENDAÑO, 2007).
Concentración de mercurio en muestras de suelo. Las concentración de mercurio determinada en la muestra por mediante técnica instrumental de absorción atómica en la Universidad de Córdoba fue de $4.9 \mathrm{mg} \cdot \mathrm{kg}-1$, según los resultados este un suelo se considera de categoría tóxico, debido a que se encuentra dentro del rango de $0,3-5 \mathrm{mg} \cdot \mathrm{kg}-1$. A esta concentración el mercurio presente en el suelo, comienza a inhibir procesos en el suelo, tales como la respiración microbiana, la mineralización y la nitrificación, según lo reportan (POSCHENRIEDER y BARCELÓ, 2003; KABATAPENDIAS, 2011). Según lo reporta ADRIANO (2001), en los suelos los valores de mercurio oscilan entre 0.01 y $0.2 \mathrm{mg} \cdot \mathrm{kg}-1$, pero estos valores pueden incrementar, significativamente, en aquellos suelos intervenidos por explotación minera.

Bacterias rizosféricas. Se aislaron cinco morfotipos de bacterias, las cuales fueron rotuladas como: M1SBLB, M2SBLIM, M3SBLIM, M4SBLIM y M5SBLIM (M: morfotipo; S: suelos; $B$ : Bolívar; LIM: laboratorio investigaciones microbiológicas universidad de Sucre), purificadas y conservadas sobre la superficie de agar nutritivo para los las pruebas y análisis respectivos. 
Crecimiento de bacterias rizosféricas a diferentes concentraciones de mercurio. Los resultados obtenidos como se observan en la Figura 2, muestran que solo el morfotipo M4SBLIM obtuvo un crecimiento de $86 \times 10^{4} \mathrm{UFC} / \mathrm{ml}$ hasta la concentración de $200 \mathrm{ppm}$, con respecto a los demás morfotipos evaluados y hasta la concentración $100 \mathrm{ppm}$ de $\mathrm{Hg}$, solo se obtuvo crecimiento de los morfotipos M2BSLIM; M3SBLIM y M5SBLIM. El morfotipo M1SBLIM, solamente mostró capacidad de resistir al mercurio en forma de cloruro de mercurio $\left(\mathrm{HgCl}_{2}\right)$ hasta las $50 \mathrm{ppm}$.

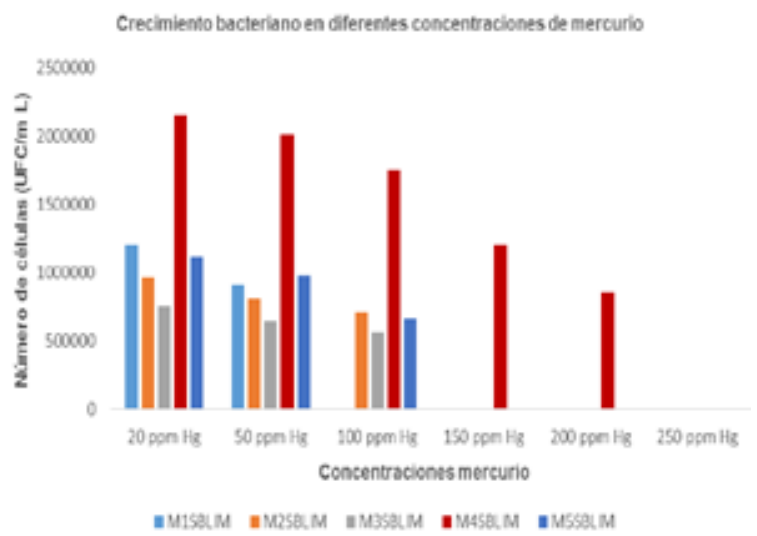

Figura 2. Crecimiento bacteriano (UFC/ $\mathrm{ml}$ ) de los morfotipos aislados de suelos de la mina Santa Cruz, Bolívar, Colombia a diferentes concentraciones de mercurio. M: morfotipos; SB: suelos mina Santa Cruz, Bolívar.

La presencia de altas concentraciones de mercurio en el medio ambiente produce una baja abundancia de comunidades microbianas. Esta situación ocurre debido a que relativamente la baja diversidad genética de las comunidades microbianas se aclimata a la presencia del mercurio e induce un cambio en la composición de las mismas comunidades (RASMUSSEN et al., 2008). Además, la tolerancia al mercurio en las comunidades microbianas aclimatadas, varía en respuestas a las diferentes concentraciones del metal en los diferentes ambientes. La resistencia de mercurio en las bacterias está determinada por la presencia del operon Mer, el cual se localiza en plásmidos, transposones, integrones y el DNA genómico y frecuentemente además en los genes resistentes a antibióticos (NASCIMENTO y CHARTONE-SOUZA, 2003).
Según lo reportado por SABRY et al., (1997); De SOUZA et al., (2006), la resistencia de bacterias a metales pesados es considerado un indicador biológico para ambientes contaminados con metales pesados. Las bacterias resistentes a mercurio potencialmente contribuyen al ciclo biogeoquímico de este metal. Pero en respuesta a una resistencia incrementada a diferentes metales, ellas representan un impacto negativo sobre la funcionalidad de los ecosistemas debido al decrecimiento de la expresión de diferentes enzimas microbianas.

Identificación. El morfotipo M4SBLIM, de acuerdo a los resultados de identificación por medio un kit api $20 \mathrm{NE}$, arrojo un $99.5 \%$ de homología con secuencias de la bacteria Pseudomonas luteola, quien fue capaz de crecer hasta 200 ppm de mercurio en forma en forma de cloruro de mercurio $\left(\mathrm{HgCl}_{2}\right)$. De otra parte en la tabla 2, se observa que el morfotipo M4SB ( $P$. luteola) mostró in vitro capacidad de producción de sideróforos y fijación biológica de nitrógeno simultáneamente, mientras que los morfotipos M1SBLIM y M5SBLIM, mostraron actividad de fijación de nitrógeno.

Como lo manifiestan CASALTA et al., (2005), Pseudomonas luteola ( $P$. luteola) es una bacteria aerobia, Gram-negativa, morfología en forma de varilla, formación de pigmento de color amarillo. El organismo es no fermentativo, oxidasa-negativo, catalasa-positivo, y crece en agar MacConkey. Esta bacteria originalmente fue denominada $P$. Luteola, pero estudios sobre la base de los bajos niveles de ADN-DNA, que fue posteriormente reclasificado como Chryseomonas luteola. Sin embargo, el análisis de las secuencias de 16S rDNA de esta bacteria, indican que nombres de género Chryseomonas, Flavimonas y Pseudomonas son sinónimos, como consecuencia, se llegó a la conclusión de que los nombres $P$. Luteola y Pseudomonas oryzihabitans debe utilizarse. El hábitat normal de $P$. Luteola no es definido, a pesar de que pertenece a un grupo de bacterias que normalmente se encuentran en el agua, el suelo, la humedad y otros entornos. Asimismo, esta bacteria ha sido considerada una bacteria saprofita, pero en ocasiones se comporta como un patógeno oportunista que causa bacteriemia, meningitis, endocarditis, peritonitis en humanos y animales. 
Levantamiento de información bibliográfica en bases de datos a nivel mundial no señalan estudios de Ps luteola con con capacidad de absorber mercurio, sin embargo, trabajos llevados a cabo por OZDEMIR y BAYSAL, (2004), señalan que $P$. luteola puede absorber ciertos metales pesados tales como $\mathrm{Cr}(\mathrm{VI})$ y $\mathrm{Al}(\mathrm{III})$, presente en aguas residuales industriales bajo condiciones relativamente ácidas $(\mathrm{pH}: 4$ y 5 para cada ion respectivamente). Los experimentos realizados por OZDEMIR, (2005), esta bacteria muestra una alta capacidad de adsorción de $55.2 \mathrm{mg}$ g-1 para Al (III) y $3.0 \mathrm{mg}$ g-1 para $\mathrm{Cr}(\mathrm{VI})$. Otros estudios han señalado que esta especie produce exopolisacárido (EPS) utilizado en la adsorción de níquel y cobre.

El presente estudio fue observada in vitro la producción cualitativa de sideróforos y fijación biológica de nitrógeno por parte de $P$. luteola (Tabla 2). La producción de sideróforos es una estrategia más común para la acumulación de hierro en los microorganismos. Como lo indican HIDER y KONG, (2010), estos compuestos son moléculas de bajo peso molecular (500-1500 Da), poseen alta afinidad y selectividad por el hierro (III). Existe alrededor de 200 compuestos con distintas estructuras identificados como sideróforos, no obstante en la naturaleza los grupos funcionales no difieren mucho entre ellos (KREWULAK y VOGUEL, 2007). Así mismo, WINKELMANN, (1987); WINKELMANN, (1991), argumentan que el papel de estos compuestos es captar hierro del medio ambiente, tornarlo disponible para la célula bacteriana y después ser secretado al medio extracelularmente. Este compuesto forma complejos con el $\mathrm{Fe}^{3+}$, que es transportado al interior de la célula para su disponibilidad del metal a la bacteria (DOBBELAERE et al., 2003). Los complejos estables entre el sideróforo y otros cationes metálicos diferentes al hierro también son formados como lo manifiestan NEUBAUER et al., (2000), ejemplos de estos complejos estables que se pueden formar entre los sideróforos y los metales fueron las evaluaciones hechas sobre 16 los siguientes metales $\mathrm{Ag}^{+}, \mathrm{Al}^{3+}$, $\mathrm{Cd}^{2+}, \mathrm{Co}^{2+}, \mathrm{Cr}^{2+}, \mathrm{Cu}^{2+}, \mathrm{Eu}^{3+}, \mathrm{Ga}^{3+}, \mathrm{Hg}^{2+}, \mathrm{Mn}^{2+}, \mathrm{Ni}^{2+}$, $\mathrm{Pb}^{2+}, \mathrm{Sn} 2+, \mathrm{Tb}^{3+}, \mathrm{Tl}^{+}$y $\mathrm{Zn}^{2+}$ y comprobaron que los dos principales sideróforos formados por la especie de bacteria Pseudomonas aeruginosa correspondieron a pioverdina y piochelina y son considerados los aptos para quelar todos estos metales (BRAUD et al., 2009 a,b).
Tabla 2. Actividad cualitativa de solubilización de fosfatos, producción de sideróforos y fijación biológica de nitrógeno de morfotipos aislados de suelos de la Mina de Santa Cruz, Bolívar, Colombia. +: actividad positiva; -: actividad negativa.

\begin{tabular}{lll}
\hline \multirow{2}{*}{ Morfotipos } & \multicolumn{2}{c}{ Actividad promotora de crecimiento } \\
\cline { 2 - 3 } & $\begin{array}{c}\text { Solubilización Producción de Fijación biológica } \\
\text { de fosfatos sideróforos de nitrógeno }\end{array}$ \\
\hline
\end{tabular}

M1SBLIM

M2SBLIM

M3SBLIM

M4SBLIM

M5SBLIM

Con respecto a la actividad de solubilización de fosfato mostrada cualitativamente in vitro por M4SBLIM, estudios llevados a cabo por SANTANAS et al., (2002), en donde aislaron bacterias del suelo asociadas a cultivos de crisantemo, señalaron la presencia de actividad de solubilización de fosfatos en las especies de bacterias identificadas como: Bacillus lenchiniformis, Pseudomonas putida y Pseudomonas luteola. Así mismo VASQUEZ et al., (2000), identificaron a cepas bacterianas asociadas a la capacidad solubilizadora de fosfato están las aisladas a partir de mangle blanco: B. licheniformis, Chryseomonas luteola (Pseudomonas luteola) y Pseudomonas stutzeri.

Según estudios realizados por GONZÁLEZ et al., (2015), sobre eficiencia de las Bacterias Promotoras del Crecimiento Vegetal (BPCV) en Caña de Azúcar, reportan a Ps. Luteola como una rizobacteria con alta capacidad de producir índoles totales después de ser inoculadas en plantas de caña de azúcar. En este sentido mismo sentido YANG et al., (2009) definen a las rizobacterias promotoras de crecimiento son microorganismos capaces de promover el crecimiento de las plantas a través de diferentes mecanismos tales como: absorción y movilidad de nutrientes, producción de antibióticos, fijación biológica de nitrógeno, la producción de fitohormonas, solubilización de fosfatos, producción de sideróforos y el control biológico sobre fitopatógenos (BASHAN y DEBASHAN, 2005). 


\section{Conclusiones}

En el presente estudio aisló a Pseudomonas luteola, de rizósfera de suelo de la mina Santa Cruz, localizada en el Sur del departamento de Bolívar. La actividad de resistencia in vitro demostró capacidad de resistir a 200 ppm de mercurio en forma de cloruro de mercurio $\left(\mathrm{HgCl}_{2}\right)$. P. luteola, presentó además capacidad de solubilizar fosfato y fijación biológica del nitrógeno. Esta bacteria fue aislada de un suelo identificado como de reacción extremadamente ácido y fuertemente salino; contenido de materia orgánico y fosforo pobre y abundante, respectivamente y contenidos nulos de calcio y magnesio. En los actuales momentos en las base de datos de bibliografías especializadas no se reporta la presencia $P$. luteola, como rizobacteria con capacidad de absorber mercurio, convirtiéndose en el primer reporte en Colombia sobre la presencia de esta bacteria adaptada a los suelos de la Mina de Santa Cruz, Bolívar con altas concentraciones de mercurio.

\section{Agradecimientos}

Los autores expresan sus agradecimientos al laboratorio de investigaciones microbiológicas de la Universidad de Sucre.

\section{Referencias}

ADRIANO, D.C. 2001. Trace elements in the terrestrial environment. Springer, New York.

BASHAN, Y.; DE-BASHAN, L. E. 2005. Bacteria/plant growthpromotion. In: D. Hillel (ed.). Encyclopedia of soils in the environment. Elsevier. Oxford. UK.

BLOOM, NS.; PORCELLA, DB. 1994. Less mercury?. Nature 367, 694

BRAUD, A.; HANNAUER, M.; MILSIN, G.L.A.; SCHALK, I.J. 2009a.The Pseudomonas aeruginosa pyochelin-iron uptake pathway and its metal specificity. Journal of Bacteriology. 191:5317-5325.

BRAUD, A.; HOEGY, F.; JEZEQUEL, K.; LEBEAU, T.; SCHALK, I.J. 2009b. New insights into the metal specificity of the Pseudomonas aeruginosa pyoverdine-iron uptake pathway. Environmental Microbioogy. 11:1079-1091.

CASIERRA-POSADA, F.; AGUILAR-AVENDAÑO, O. 2007. Estrés por aluminio en plantas: reacciones en el suelo, síntomas en vegetales y posibilidades de corrección. Rev. Col. Ciencias Hort. 1(2):246-257.

CASALTA, J.P.; FOURNIER, P.E.; HABIB, G.; RIBERI, A.; RAOULT, D. 2005.Válvula protésica endocarditis causada por Pseudomonas luteola. BMC Infectious Diseases. 2005; 5: 82-82. Disponible en: URL: http://viaclinica.com/article.php?pmc id =1274313

CHUNG, S.; CHON, HT. 2014. Assessment of the level of mercury contamination from some anthropogenic sources in Ulaanbaatar, Mongolia. J. Geochem. Explor. 147: 237-244.

DE SOUZA, MJ.; NAIR, S.; LOKA BHARATHI, PA.; CHANDRAMOHAN, D., 2006. Metal and antibioticresistance in psychrotrophic bacteria from Antarctic Marine waters. Ecotoxicology 15: 379-384.

DOBBELAERE, S.; VANDERLEYDEN, J.; OKON, Y. 2003. Plant Growth-Promoting Effects of Diazotrophs in the Rhizosphere. Critical Reviews in Plant Sciences. 22(2):107-149. 
GERHARDT, KE.; HUANG, XD.; GLICK, BR.; GREENBERG, BM. 2009. Phytoremediation and rhizoremediation of organic soil contaminants: potential and challenges. Plant Sci 176: 20-30.

GONZÁLEZ, A .M.; ESPINOSA, V. D.; GÓMEZ, M. F. 2015. EFFICIENCY OF PLANT GROWTH PROMOTING RHIZOBACTERIA (PGPR) IN SUGARCANE. Revista Terra Latinoamericana. 33: 321-330.

HIDER, R.C.; KONG, X. 2010. Chemistry and biology of siderophores. Natural Product Reports. 27:637-657.

INSTITUTO GEOGRÁFICO AGUSTÍN CODAZZI -IGAC-. 2015. ¿Cómo realizar la toma de muestras para suelos? Disponible desde internet en: http://www.igac.gov. co/wps/portal/igac/raiz/iniciohome/ tramites/!ut/p/c4/04_SB8K8xLLM9MSSzPy8xBz9CP0os3hHT3d_JydDRwN3t0BXA0_vUKMwf28PI4NQI 2CbEdFAJ67NCc!/?WCM_PORTLET=PC_7_AIGOBB1A08AGF̄0ISG6J8NS30 (con acceso26/10/2016).

KABATA-PENDIAS, A. 2011. Trace elements in soils and plants. 4th ed. CRC Press, Boca Ratón (Estados Unidos).

KREWULAK, K.D.; VOGEL, H.J. 2007. Structural biology of bacterial iron uptake. Biochimica et Biophysica Acta. 1778:1781-1804.

NASCIMENTO, A.M.A.; CHARTONE-SOUZA, E. 2003. Operon mer: bacterial resistance to mercury and potential for bioremediation of contaminated environments. Gen. Mol. Res. 2: 92-101.

MATHEMA, VB.; THAKURI, BC.; SILLANPÄÄ, M. 2011. Bacterialmer operon-mediated detoxification $\mathrm{f}$ mercurial compounds: a short review. Arch Microbiol 193: 837-844.

MURATOVA, A.; HŸBNER, TH.; TISCHER, S.; TURKOVSKAYA, O.; MÖDER, M.; KUSCHK, P. 2003. Plant-Rhizosphere - Microflora association during phytoremediation of PAH -contaminated soil. Int. J. Phytoremediat. 5:137-151.

OZDEMIR, G.; BAYSAL, S. H. 2004. "Chromium and aluminum biosorption on Chryseomonas luteola TEM05”. Applied Microbiology and Biotechnology. 64 (4): 599-603.

OZDEMIR, G.; CEYHAN, N.; MANAV, E. 2005. "Utilization of an exopolysaccharide produced by Chryseomonas luteola TEM05 in alginate beads for adsorption of cadmium and cobalt ions". Bioresource Technology. 96 (15): 1677-82

PAISIO, C.E.; GONZÁLEZ, P.S.; TALANO, M.A.; AGOSTINI, E. 2012. Remediación biológica de Mercurio: Recientes avances. Rev Latinoam Biotecnol Amb Algal 3(2):119-146.

PÉREZ, AC.; TUBERQUÍA, SA.; AMELL, JD. 2014. Actividad in vitro de bacterias endófitas fijadoras de nitrógeno y solubilizadoras de fosfatos. Agron. Mesoam. 25:01-11.

PÉREZ, A.; MARTINEZ, D.; ZAFIRO, B.; MARRUGO, J. 2016. Bacterias endófitas asociadas a los géneros Cyperus y Paspalum en suelos contaminados con mercurio. Rev. U.D.C.AAct. \& Div. Cient. 19(1): 67-76.

PÉREZ C. A.; ARROYO C. E.; CHAMORRO A. L. 2017. Bacterias endófitas aisladas de cultivo de arroz. Editorial Académica Española, España.

POSCHENRIEDER, C.; BARCELÓ, J. 2003. Estrés por metales pesados. In: REIGOSa, MJ., PEDROL, N., SÁNCHEZ, A. (eds.). Ecofisiología Vegetal. Madrid. 
UNEP, 2013. Global Mercury Assessment 2013: Source, Emissions, Releases and Environmental Transport.

RATHNAYAKE, IVN.; MALLAVARAPU, M.; KRISHNAMURTI, GSR.; BOLAN, NS.; NAIDUR R. 2013. Heavy metal toxicity to bacteria - Are the existing growth media accurate enough to determine heavy metal toxicity. Chemosphere. 90:1195-1200.

RASMUSSEN, LD.; ZAWADSKY, C.; BINNERUP, SJ.; OREGAARD, G.; SORENSEN, SJ.; KROER, N., 2008. Cultivation of hard to culture subsurface mercury resistant bacteria and discovery of new mera gene sequences. Appl. Environ. Microbiol. 74 (12): 3795-3803.

SANTANA, M.; VÁSQUEZ, C.; MARTÍNEZ, M.; FRANCO, M. 2002. Evaluación de cepas de Azotobacter spp y de bacterias solubilizadoras de fosfato (BFS), como bifertilizante mixto en cultivos de crisantemo (Chrysoanthemum morifolium var. Regal Suerte). Tesis de Microbiologia Industrial. Pontificia Universidad Javeriana. 24 p.

SABRY, SA.; GHOZLAN, HA.; ABOU-ZEID, DM. 1997. Metal tolerance and antibiotic resistance patterns of a bacterial population isolated from sea water. Journal Applied and Microbiology. 82, 245-252.

SCHWYN, B.; NEILANDS, J. (1987). Universal chemical assay for the detection and determination of siderophores. Anal Biochem 160: 47-56.

WANG, J.; FENG, X.; ANDERSON, C.W.; XING, Y.; SHANG, L. 2012. Remediation of mercury contaminated sites - A review. J Hazard Mater 221-222:1-18.

WINKELMANN, G.; VAN DER HELM, D.; Neilands, J. B. 1987. Iron Transport in Microbes, Plants and Animals, VCH Press, Weinheim.

WINKELMANN, G. 1991. Handbook of Microbial Iron Chelates, CRC Press, Boca Raton, FL, 1991.

YANG, J.; KLOEPPER J. W.; RYU, C. M. 2009. Rhizosphere bacteria help plants tolerate abiotic stress. Trends Plant Sci. 14: 1-4.

YASUTAKE, A.; CHENG, JP.; KIYONO, M.; URAGICHI, S.; LIU, X.; MUIRA, K.; Yasuda, Y.; MASHYANOV, N. 2011. Rapid monitoring of mercury in air from an organic chemical factory in China using a portable mercury analyzer. The Scientific World JOURNAL 11:1630-1640.

ZHANG, HH.; CHEN, JJ.; ZHU, L.; YANG, GY., LI, D.Q., 2014. Anthropogenic mercury enrichment factors and contributions in soils of Guangdong Province, South China.J. Geochem. Explor. 144:312-319.

ZHOU, J.; WANG, Z.; ZHANG, X.; CHEN, J., 2015. Distribution and elevated soil pools ofmercury in an acidic subtropical forest of southwestern China. Environ. Pollut. 202, 187-195. 